\title{
Oxchuc, Chiapas: representación política y peritaje antropológico
}

\author{
Oxchuc, Chiapas: Political representation and \\ expert witness anthropological reports \\ Elisa Cruz Rueda* \\ Universidad Autónoma de Chiapas, Campus iII, San Cristóbal de las Casas, Chiapas, México \\ ORCID: https://orcid.org/o0oo-0002-6339-I5I8 \\ Natalie Long * \\ Investigadora independiente, Springfield, Illinois, Estados Unidos \\ ORCID: https://orcid.org/0000-0003-0885-I865 \\ ISSN-OI85-4259; e-ISSN: 2007-9I76 \\ DoI: http://dx.doi.org/IO.28928/ri/892020/aotI/cruze/long
}

\begin{abstract}
Resumen
Abordamos el caso de Oxchuc, Chiapas, a partir de los documentos generados por los distintos actores, principalmente el Instituto de Elecciones y Participación Ciudadana, una parte organizada políticamente de los pobladores y el Tribunal Electoral del Estado de Chiapas. El caso es interesante porque, a diferencia de los de Oaxaca y Cherán, en este se conjunta el uso del peritaje antropológico (llamado dictamen porque no se presentó en un proceso jurisdiccional como prueba) y del mecanismo de consulta ciudadana para establecer la pertinencia del cambio de sistema de partido por el llamado de usos y costumbres o gobierno indígena. El contexto histórico y jurídico está dado por las reformas de $200 \mathrm{r}$ al artículo $2^{\circ}$ de la Constitución Política de los Estados Unidos Mexicanos (CPEUM) que retoma el reconocimiento y el respeto a la autonomía y libre determinación de los indígenas y sus pueblos, que quedaron incorporados al marco jurídico mexicano desde 1990 con la firma y ratificación del Convenio 169 de la Organización Internacional del Trabajo, y posteriormente transitando por el artículo $4^{\circ}$ de la CPEUm. El caso es relevante por ser cada vez más recurrente por parte de indígenas y sus pueblos que se haga uso de los mecanismos no solo legales sino jurisdiccionales en la exigencia de sus derechos.
\end{abstract}

Palabras claves: Estado, Derechos Humanos y Derechos indígenas

\begin{abstract}
We examine the case of Oxchuc, Chiapas, based on the documents generated by different entities, particularly the Institute of Elections and Citizen Participation, the Electoral Tribunal of the State of Chiapas, and a politically organized part of the town's population. The case is interesting because unlike the cases of Oaxaca and Cherán - which in another work we contrast with Oxchuc (Cruz and Long, publication pending), here the use of anthropological expert reports and citizen consultation mechanisms are used together to establish the propriety of changing the governing system from that of political parties to the system of Uses and Customs, or indigenous government. The historical and legal context is provided by the reforms of $200 \mathrm{I}$ to Article 2 of the Political Constitution of the United Mexican States (CPEUM), which reclaims recognition and respect for the autonomy and self-determination of indigenous peoples and their communities; these elements have been incorporated into the Mexican legal framework since 1990 with the signing and ratification of Convention I69 of the International Labor Organization, and subsequently incorporated through Article 4 of the среим. This case is relevant because indigenous peoples and their communities are increasingly making use of legal and jurisdictional mechanisms in the demand for their rights.

Keywords: State, Human Rights and Indigenous Rights
\end{abstract}

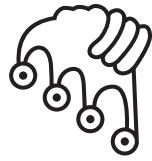

IZTAPALAPA

Agua sobre lajas

*elisacruzrueda@hotmail.
com
** long.natalie@gmail.com 


\section{Introducción}

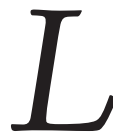

a Constitución Política de los Estados Unidos Mexicanos en su artículo $2^{\circ}$ reconoce el principio de diversidad cultural y la deposita en los pueblos indígenas. Este pincipio se relaciona con otros como el de pluriculturalidad y el del pluralismo jurídico; de igual forma, implica derechos y responsabilidades a indígenas y sus pueblos. Y por parte del Estado, obligaciones: fundamentalmente, adecuar o alinear el marco jurídico mexicano a la normativa internacional en materia de derechos humanos en general y específicamente de derechos de los indígenas y sus pueblos. En este sentido, es importante subrayar que los derechos de indígenas y sus pueblos forman parte del sistema internacional y americano de derechos humanos.

Los Acuerdos de San Andrés de 1996 fue el primer intento de aterrizar esos derechos, seguido por los reclamos por parte de los indígenas en materia electoral en otros estados de la república mexicana. En algunos casos esos reclamos por vía jurisdiccional han provocado sentencias adversas o a favor, o bien, tensiones por los cambios que implican en las dinámicas de relación entre el Estado mexicano y los pueblos indígenas en lo local. En el caso chiapaneco se localiza la tensión, por un lado, entre el afán del gobierno del estado de Chiapas de sostener poderes locales (caciquiles o de facto), y por otro dar cumplimiento al Sistema Internacional de Derechos Humanos que abarca los derechos civiles, políticos, económicos y culturales de los indígenas, y que están reconocidos en la Constitución (CPEUM).

En este sentido es pertinente señalar la complejidad de los procesos de apropiación de instituciones como el municipio y, por lo tanto, la elección de autoridades. Varios autores y autoras (Rus, 1995; Recondo, 2007; Burguete, 20II; Sieder y Sierra, 20II) muestran que al margen de las posturas sobre el origen colonial de la institución municipal, los procesos para su apropiación por indígenas y sus pueblos se complejizan, al verse atravesados por la instauración del Estado mexicano y su relación con las comunidades agrarias mediante la reconfiguración de cacicazgos y el corporativismo campesino y magisterial, que tienen bases históricas y geográficas diversas, tomando rumbos distintos en cada una de las regiones y entidades federa- 
tivas del país. El caso concreto de Oxchuc no es ajeno a esto, y la especificidad de la forma en que el Estado se ha instaurado en Chiapas y cómo estableció su relación con los pueblos indígenas explica las semejanzas y diferencias entre Oxchuc y otros procesos similares que se han dado en otras partes del país.

El Estado posrevolucionario establece un modo original de integración política que pasa ante todo por el vínculo clientelista. La articulación con las comunidades rurales se hace a través de una serie de intermediarios, los caciques. Éstos constituyen la piedra angular del pacto clientelista que une al Estado modernizante con las comunidades, al mismo tiempo que garantizan a éstas un margen suficiente de autonomía para reproducir su diferencia institucional y cultura a la sombra de la ley. [...] Como Jano, el cacique tiene dos caras: la de la sociedad local, de la que surge y que representa ante el Estado, y la del Estado cuyo emisario es frente a la sociedad local. En las zonas donde la población indígena es mayoritaria ocurre generalmente que el cacique sea indígena (Recondo, 2007: 57).

La coyuntura de Oxchuc da razón de esas tensiones, sobre todo porque se pone en entredicho la pertinencia de la aplicación de un sistema electoral y de participación ciudadana que no contempla la especificidad social, política, histórica, étnica o de culturas locales y que, por lo tanto, se muestra ajeno a las dinámicas comunitarias indígenas.

$\mathrm{Al}$ exponer los sistemas internos de designación de autoridades en Oxchuc se describe la manera en que se elegían las autoridades antes de la imposición del sistema electoral mexicano y la legitimidad que estas adquirían por surgir de procesos en los que la voluntad general se expresaba y respetaba. [...] A lo largo de la historia la estructura político-administrativa de Oxchuc se ha organizado de manera tal que los habitantes de las comunidades rurales podían aspirar a formar parte de la administración municipal pues se alternaban los cargos de la autoridad municipal a través de la existencia de dos calpules o barrios que lo dividían: el calpulli grande o primero llamado B'ikit calpul y el calpulli chico o segundo llamado Magul calpul. (Jiménez y Ocampo, 2019: 50-51).

En otras palabras, los mecanismos electorales de participación son insuficientes y culturalmente inadecuados para promover el cumplimiento y respeto de los derechos políticos de los indígenas y sus pueblos. El caso chiapaneco es particular porque además de contener un crisol de contradicciones entre el discurso oficial de derechos 
humanos y su cumplimiento, existen dinámicas sociales y políticas que lo diferencian de las realidades de otros estados, como Oaxaca o Michoacán (Cruz y Long, en prensa). Es decir, encontramos un reconocimiento de los derechos indígenas, pero sin mecanismos que garanticen su cumplimiento.

Y si existe el reconocimiento de ese derecho a nivel internacional y nacional, nos preguntamos: ¿qué intereses motivan que no se establezcan los mecanismos jurídicos y políticos apropiados para concretar y hacer efectivo su ejercicio? Si los derechos no se negocian, ¿por qué los gobiernos esperan que los indígenas y sus pueblos exijan sus derechos más cuando se ha llegado a niveles de violencia social de tal magnitud que ya no permiten su concreción? En el apartado correspondiente de este trabajo trataremos si no de responder, sí de plantear algunas reflexiones que guíen a posibles respuestas.

Para exponer el caso y desarrollar su análisis separamos dos partes. En la primera, De los Acuerdos de San Andrés al marco jurídico en materia de elección de representantes en Chiapas, exponemos a grandes rasgos cómo este reclamo se incorpora en los Acuerdos, y posteriormente analizamos el marco normativo en materia de elección de autoridades indígenas o sistema de usos y costumbres y su relación con el Derecho a la Consulta en el Estado de Chiapas. En la segunda parte, El peritaje antropológico y la consulta en su relación con la participación política en Oxchuc, explicamos a grandes rasgos nuestros hallazgos en la revisión de los instrumentos legales arriba señalados, para concluir con algunas Reflexiones finales.

\section{De los Acuerdos de San Andrés al marco jurídico en materia de elección de representantes en Chiapas}

Nos referimos a este suceso histórico como arena pública de disputa por los derechos de indígenas y sus pueblos, entre ellos: a usar preferentemente su lengua y a tener y aplicar su propio derecho.

El proceso de diálogo de San Andrés estuvo antecedido por los diálogos de la Catedral y los de San Miguel. Durante este proceso la Comisión Nacional de Intermediación (CONAI) tuvo que hacer grandes esfuerzos por comunicar entre las partes la postura de cada una (EZLN-gobierno federal y del estado de Chiapas), lo cual se volvía más complejo por la traducción de los idiomas o lenguas indígenas al español y por el respectivo sentido de mundo.

Un evento que presenciamos directamente (por formar parte del cuerpo de asesores de conaI) es ejemplo de cómo los conceptos de las arenas tanto política 
como jurídica: soberanía y monismo jurídico, estuvieron a revisión y bajo la lupa de las demandas indígenas.

Los llamados diálogos de San Andrés se diseñaron para desarrollarse en cuatro mesas, y solo se realizó la primera: Derechos y cultura de los pueblos indígenas. Esta mesa se subdividió en varias. En una de ellas: Derechos de los indígenas y sus pueblos, los asesores de los militantes zapatistas plantearon: "los indígenas tienen derecho a sus propios derechos, y uno de ellos es el derecho a ejercer su propia jurisdicción y sistemas normativos". A esto el gobierno federal señaló: "no es potestad de los individuos y gobernados generar normas, eso es potestad del Estado".

Con lo anterior lo que se ponía a discusión era el monismo jurídico que plantea que solo existe un centro generador de normas y por lo tanto un centro generador para su aplicación a través de la coacción. De esta manera, el concepto de soberanía también se sometía a revisión porque la generación de normas y su ejercicio implican: población, territorio y un poder político que el Estado mexicano reclamaba en exclusiva para sí y los "indios" cuestionaron ese monopolio.

Parte del relativo éxito de que los indígenas pudieran hacer semejantes planteamientos fue el hecho del alzamiento del Ejército Zapatista de Liberación Nacional (EZLN) en 1994, que declaró la guerra al gobierno mexicano, pero también lo fue que desde 1990 se había firmado y ratificado el Convenio i69 de la Organización Internacional del Trabajo. Además de que los intelectuales indígenas y sus aliados aprendieron la lección: poner en lenguaje y términos jurídicos el sentir de los indígenas y sus pueblos, haciendo a un lado aquello que causara resquemor y temor, lo que facilitó el diálogo y negociación, pero tuvo un costo muy grande.

Lo anterior se hace patente a 23 años de la firma de los Acuerdos de San Andrés. El diálogo entre el gobierno o sus instituciones con los indígenas siguen siendo en la lengua dominante que es el español y domina la lógica estatista.

\section{ILUSTRACIÓN I.}

Pensamiento estatista.

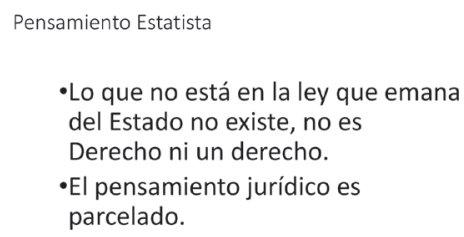

Elaboración propia. 
De igual forma, no se da apoyo a la política lingüística expresada en la formación y profesionalización de intérpretes-traductores; los indígenas y sus pueblos han tenido que relegar del debate y del acceso a la justicia aquellos "asuntos" que son incomprensibles al derecho estatal, como lo es la brujería y el ámbito de lo espiritual como elemento que también debe considerarse parte de los sistemas normativos indígenas y en el hacer justicia, y ambos como ejercicio de libre determinación y de autonomía.

$\mathrm{Al}$ ser la población del municipio de Oxchuc en su mayoría indígena, la toma de decisiones políticas implica la coexistencia del sistema jurídico hegemónico y el sistema jurídico alterno.

El derecho electoral indígena de Oxchuc se integra por el conjunto de leyes y procedimientos propios vigentes que rigen el nombramiento de las diversas autoridades comunitarias, que, dicho sea de paso, parte de premisas diversas a las que sustenta el sistema de partidos políticos (Jiménez y Ocampo, 2019: 53).

\section{ILUSTRACIÓN 2.}

Las dimensiones y planos del sentido de mundo.

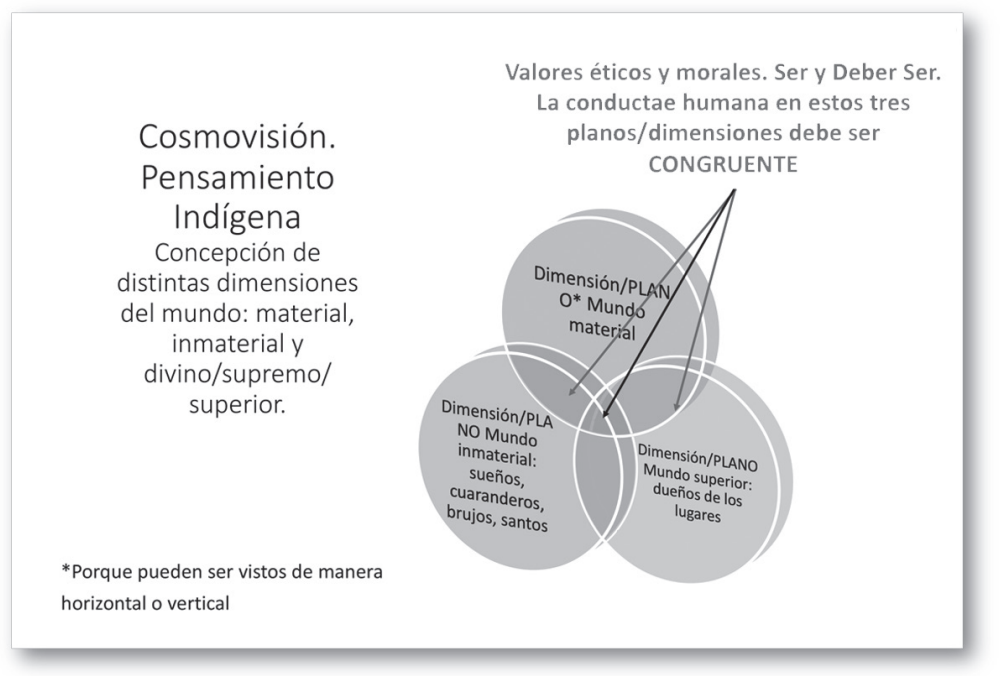

Elaboración propia. 
Es decir, el pensamiento estatista se ha impuesto sobre el principio constitucional de la diversidad y la interculturalidad y pese a lo que se señala en la среUм como reconocimiento del principio del pluralismo jurídico. De esta manera, continúa el monismo jurídico parcelado, con lo cual las instituciones del Estado y el gobierno atienden de la misma forma los "asuntos" que involucran a indígenas y sus pueblos: ambiental, agrario, salud, agua, educación... y en el caso que abordamos, la elección de autoridades.

ILUSTRACión 3.

Pensamiento estatista

\section{Pensamiento Estatista}

Cada institución tiene ámbitos de competencia señalados por la materia de su intervención -cultura, tierras, medio ambiente, recursos naturales, recursos bióticos- que muchas veces obstaculiza el cumplimiento de los derechos humanos

Elaboración propia.

Los Acuerdos de San Andrés constan de tres documentos: Declaración conjunta, Acuerdos a nivel Federal y Acuerdos a nivel del estado de Chiapas. Es importante subrayar que el proceso de diálogo que dio lugar a estos acuerdos no tenía precedentes y nunca más se repitió; como proceso dialogado, es el antecedente de un verdadero mecanismo de consulta.

Exponemos a grandes rasgos el contenido de los Acuerdos de San Andrés, directamente relacionados con el tema central de este trabajo: 


\section{ILUSTRACIÓN 4.}

Pendientes en el cumplimiento de los Acuerdos de San Andrés.

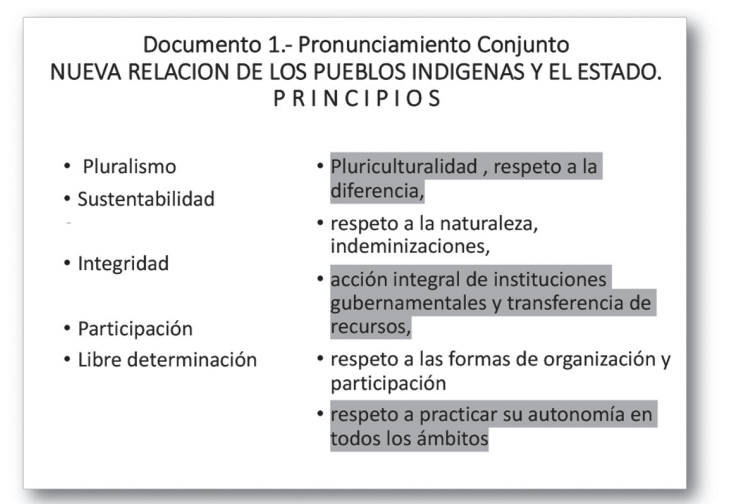

Elaboración propia.

Lo que aparece sombreado es lo que consideramos que no se ha cumplido por parte del Estado mexicano. Y concretamente, de la Ilustración 3 podemos observar el punto de libre determinación, que señala: respeto a practicar su autonomía en todos los ámbitos; nosotros agregamos que el de elección de autoridades es uno de ellos y si bien ya ha sido incluido en la CPEUM, no se ha hecho efectivo y el caso de Oxchuc es una muestra.

\section{ILUSTRACIÓN 5 .}

Pendientes en el cumplimiento de los Acuerdos de San Andrés.

\section{Documento 1.- Pronunciamiento Conjunto COMPROMISOS}

- Reconocer a los Pueblos Indígenas en la Constitución

- Ampliar la participación y representación política

- Garantizar el acceso pleno a la justicia

- Promover las manifestaciones culturales de los Pueblos Indígenas

- Asegurar la educación y la capacitación

- Garantizar la satisfacción de las necesidades básicas

- Impulsar la producción y el empleo

- Proteger a los indígenas migrantes

Elaboración propia. 
La elección de autoridades bajo los mecanismos internos de una comunidad o pueblo indígena es lo que se conoce como elección por usos y costumbres. Este derecho está reconocido en el artículo 8 punto 2 del Convenio 169 de la Organización Internacional del Trabajo (Ci69), en el artículo 20 de la Declaración de las Naciones Unidas sobre los Derechos de los Pueblos Indígenas (la Declaración), y el artículo $2^{\circ}$ de la CPEUM. Son tres ordenamientos cuyos artículos están relacionados por los principios de unidad y coherencia (Figueroa, 2009), para hacer posible la obligación del Estado de tomar en cuenta y respetar los derechos de indígenas y sus pueblos. Esto incluye sus formas de organización y decisión como ejercicio de la libre determinación y expresión de la autonomía señalados en el artículo $2^{\circ}$ de la CPEUM. En primer lugar, los funcionarios y órganos de gobierno deberán conocerlas allegándose información de los indígenas y sus pueblos y dictámenes de expertos en la materia como lo es el peritaje antropológico y la consulta (Cruz, 2013; 2009). De esta manera, los Estados se obligan a consultar a los pueblos indígenas cuando las decisiones del gobierno o de los poderes del Estado afecten sus derechos fundamentales a la tierra, el territorio, la autonomía, sus formas de organización, o a tener un derecho propio. Por ello los indígenas y sus pueblos han tomado el derecho a la consulta como argumento y discurso contestatario contra los intentos del Estado mexicano de afectar sus derechos territoriales y de autonomía. En el caso de Oxchuc, Chiapas, este uso contestatario se concretó en la solicitud de cambio del sistema de partidos por el de usos y costumbres para la elección de autoridades (Aristegui noticias, enero 22 de 2018).

\section{La CPEUM y los derechos indígenas}

El caso de Oxchuc se da en un contexto de reconocimiento amplio de los derechos humanos y derechos de los pueblos indígenas, en el que se relacionan la elección de autoridades indígenas y el sistema de usos y costumbres con el derecho a la consulta en el estado de Chiapas.

Sin embargo, un punto de confluencia entre Cherán y Oxchuc es la falta de mecanismos legales y de política pública local o estatal sobre las expresiones de autonomía, que se deriva a las legislaturas de los estados como se señala en el $4^{\circ}$ parrafo, preámbulo del articulo $2^{\circ}$, de la CPEUM.

Este derecho a la libre determinación está íntimamente relacionado con la elección de autoridades propias de indígenas, sus comunidades y pueblos: 
A. Esta Constitución reconoce y garantiza el derecho de los pueblos y las comunidades indígenas a la libre determinación y, en consecuencia, a la autonomía para:

I. Decidir sus formas internas de convivencia y organización social, económica, política y cultural. [...]

III. Elegir de acuerdo con sus normas, procedimientos y prácticas tradicionales, a las autoridades o representantes para el ejercicio de sus formas propias de gobierno interno, garantizando que las mujeres y los hombres indígenas disfrutarán y ejercerán su derecho de votar y ser votados en condiciones de igualdad [...]

VII. Elegir, en los municipios con población indígena, representantes ante los ayuntamientos. (fracciones I, III y VII, apartado A del artículo $2^{\circ}$, CPEUM)

\section{La Materia Electoral y los derechos indígenas}

Existe como ley reglamentaria de la materia electoral la Ley General de Instituciones y Procedimientos Electorales (LGIPE), publicada el 23 de mayo de 20I4, y que se aplica a los indígenas y sus pueblos. En su artículo 26 señala:

3. Los pueblos y comunidades indígenas tienen derecho a elegir, en los municipios con población indígena, representantes ante los Ayuntamientos. Las constituciones y leyes de las entidades federativas reconocerán y regularán estos derechos en los municipios, con el propósito de fortalecer la participación y representación política de conformidad con sus tradiciones y normas internas.

4.Los pueblos y comunidades indígenas en las entidades federativas elegirán, de acuerdo con sus principios, normas, procedimientos y prácticas tradicionales, a las autoridades o representantes para el ejercicio de sus formas propias de gobierno interno, garantizando la participación de hombres y mujeres en condiciones de igualdad, guardando las normas establecidas en la Constitución, las constituciones locales y las leyes aplicables.

En el ámbito estatal existen la Constitución Política del Estado Libre y Soberano de Chiapas (CPEchis), concretamente el artículo $7^{\circ}$ (2016) en materia indígena, seguido por la Ley de Derechos y Cultura Indígena, que no hace mención alguna de la consulta ni sobre elección de autoridades indígenas con base en el sistema interno o de usos y costumbres. Esto es importante porque, como lo señala Burguete (2017) y como se apunta arriba, al abordar el caso de Oxchuc, la falta de mecanismos para 
el efectivo reconocimiento y ejercicio de los derechos indígenas en materia electoral fue uno de los argumentos del Instituto de Elecciones y Participación Ciudadana (IEPC) para negarse a resolver sobre el cambio del sistema de partidos al sistema de usos y costumbres. Esto a pesar de que, como se ha visto, ya existía la resolución de la Suprema Corte sobre Cherán desde noviembre de 20II.

La mención al derecho de elegir autoridades internas por usos y costumbres se encuentra en el CPECHis:

Chiapas es un Estado Democrático de Derecho de composición pluricultural que reconoce los sistemas normativos internos de sus pueblos y comunidades indígenas, de acuerdo a lo establecido en esta Constitución y en la Constitución Política de los Estados Unidos Mexicanos y está comprometido con la protección de su biodiversidad ( $2^{\circ}$ párrafo, artículo $7^{\circ}$, CPEchis).

Esto, de acuerdo con Burguete (2017), es un triunfo para el reconocimiento de la autonomía indígena:

El derecho de Oxchuc a nombrar a sus autoridades municipales sin la injerencia de los partidos políticos se sostiene sobre una sólida base jurídica que se funda en el "derecho madre": el principio del derecho a la libre determinación y autonomía, fundamentado tanto en el derecho internacional ... como en la legislación nacional y local (Burguete, 2017).

Sin embargo, no existe en el Código Electoral del Estado de Chiapas, y por tanto no se ha establecido, un mecanismo reconocido de elección de autoridades por sistema indígena interno o usos y costumbres. Tampoco se hace mención del derecho de los indígenas y sus pueblos a ser consultados, aunque hay más de 115 menciones a consulta, pero no como derecho ciudadano distinto del plebiscito o de la consulta popular. En otras palabras:

Por estas omisiones la autoridad electoral del estado negó a Oxchuc su derecho a elegir a sus autoridades propias, cuando se lo fue a solicitar. $\mathrm{Al}$ responder a la demanda de Oxchuc el IEPC manifestó que "la solicitud que ahora se realiza no se encuentra reglamentada en el Código local comicial". Adicionalmente justificó la negativa en que "no existían las condiciones sociales necesarias para efectuar la consulta respectiva a los habitantes de ese municipio derivado de la disputa que existe en la integración de la autoridad municipal". Argumentos todos ellos planteados en el Acuerdo del io 
de febrero 2017 dado a conocer por el Consejo General del Instituto de Elecciones y Participación Ciudadana [IEPC/CG-A/005/2017] (Burguete, 2017).

Por ello Burguete (2017) afirma que tal omisión sobre el reconocimiento de los derechos indígenas en materia electoral denota una gran brecha entre los niveles nacional e internacional con respecto al del estado de Chiapas en materia indígena, sobre todo en la arena de los derechos civiles y políticos, es decir, este estado de la república se encuentra rezagado en cuanto a reconocimiento y cumplimiento de derechos de los pueblos indígenas.

\section{El peritaje/dictamen antropológico y la consulta en su relación con la participación política en Oxchuc}

El peritaje (o dictamen) antropológico importa para el caso de Oxchuc porque justamente la sentencia del Tribunal Electoral de Chiapas ordena que se haga $y$ posteriormente se implemente una consulta para determinar si los ciudadanos de Oxchuc optan por el cambio de sistema de elección. En este apartado solo nos referiremos al peritaje/dictamen, y en el siguiente abordaremos la consulta tal cual fue ordenada por el tribunal y ejecutada. Esto porque en varios trabajos (Cruz, 2008; 2009) hemos hecho referencia a que la consulta en términos del Convenio I69 de la oit (artículos 6 y 7 ) es un proceso de diálogo entre el Estado, los indígenas y sus pueblos, con la finalidad de llegar a un acuerdo. Pero en Oxchuc fue utilizado el mecanismo de consulta en su modalidad de consulta ciudadana, para que los pobladores decidieran si cambiaban su sistema de elección de autoridades (López, 20I8).

Los orígenes del peritaje antropológico son anteriores a la reforma del artículo $4^{\circ}$ de 1992, precisamente a las solicitudes de jueces y ministerios públicos para que un antropólogo certificara si, dentro de un procedimiento judicial o jurisdiccional, una persona que se decía indígena lo era o no. Esta práctica se ha ido modificando poco a poco y ha sido producto de la exigencia de los actores locales y del diálogo entre juristas y antropólogos.

En la actualidad, la base normativa del peritaje la tenemos en el artículo $2^{\circ}$ de la CPEUM, concretamente en su apartado A:

A. esta constitución reconoce y garantiza el derecho de los pueblos y las comunidades indígenas a la libre determinación y, en consecuencia, a la autonomía para: $[\ldots]$ 
viII. acceder plenamente a la jurisdicción del estado. Para garantizar ese derecho, en todos los juicios y procedimientos en que sean parte, individual o colectivamente, se deberán tomar en cuenta sus costumbres y especificidades culturales respetando los preceptos de esta constitución. Los indígenas tienen en todo tiempo el derecho a ser asistidos por intérpretes y defensores que tengan conocimiento de su lengua y cultura.

Podemos decir que el peritaje antropológico es un dictamen emitido por un conocedor o experto en la cultura de los «otros», en este caso, de los indígenas, dentro de un proceso jurisdiccional y que puede ser solicitado por el juez o las partes para demostrar algún punto de la litis. Se convierte en un medio de prueba cuando es solicitado por el juzgador o por una de las partes actoras en un procedimiento judicial (y es cuando lo llamamos peritaje), sobre todo de carácter penal —aunque también se ha utilizado en materia agraria, por lo que respecta a la paleografía de documentos precoloniales y coloniales, en los cuales los pueblos sustentan la propiedad de sus tierras-, y en últimas fechas en materia electoral. En el caso de Oxchuc no es peritaje porque aunque se elabora y presenta en cumplimiento de una resolución judicial, ya no forma parte de las pruebas del juicio. A continuación exponemos un resumen de lo que han sido los peritajes antropológicos en materia electoral en México:

\section{ILUSTRACIÓN 6.}

\section{Los peritajes sobre derechos político-electorales de los pueblos indígena (1)}

- Orlando Andrade (UNAM) y Colectivo Emancipaciones.

- 2 nov. 2011. JDC. Sentencia favorable que el municipio elija de acuerdo a sus usos y costumbres.

- Por otra parte, la resolución tiene una implicación electoral autonómica : Los procesos de INSTAURACIÓN de autoridades comunitarias no tienen por qué apegarse a los términos estrictos de la ley electoral, y el Instituto Nacional Electoral tiene la obligación de registrar a los candidatos que presente la comunidad.

- La SCJN determinó que las comunidades indígenas tienen una protección especial del Estado, por lo que invalidó las reformas constitucionales de esa entidad, aprobadas sin consultar a la comunidad.

Elaboración propia. 
ILUSTRACIÓN 7 .

\section{Los peritajes sobre derechos político-electorales de los pueblos indígena (2)}

2012. Teresa Sierra (CIESAS), municipio de San Luis Acatlan, Guerrero. Siguiendo los lineamientos dados por el IEPC, se emitieron 130 actas de comunidades a favor de elegir a sus autoridades a través de sus actas tradicionales. EI IEPC las rechazó. Comenzó la batalla en los tribunales a través de los JDC. Acatlán gana en el tribunal y ordena al IEPC a realizar la consulta.

2015. Se realiza la consulta. La votación no favoreció al sistema electoral de usos y costumbres. Se denunció intervención de los partidos políticos.

Elaboración propia.

ILUSTRACión 8.

\section{Los peritajes sobre derechos político-electorales de los pueblos indígena (3)}

- Maribel Nicasio y José Jaime Torres (2015). Caso Ayutla de los Libres, Guerrero.

- El 26 de junio de 2014, autoridades comunitarias solicitaron al IEPC elegir a sus autoridades mediante usos y costumbres. El IEPC respondió un año después, que no atendería la petición, debido a que el proceso electoral se encontraba en curso.

- Habitantes de ese municipio, promovieron JDC's. El resolutivo fue a su favor.

- En octubre de 2015 comenzaron asambleas. Los partidos impugnaron. Se declaró nulos todos los actos. Comenzó un nuevo proceso de consulta, en el que están ahora hacia 2018.

Elaboración propia. 
En resumen, el peritaje/dictamen antropológico es:

- Herramienta que contribuye a la inclusión de la diferencia cultural en la norma jurídica, en las decisiones de gobierno y de Estado y en la justicia dirigidos a los indígenas y sus pueblos.

- No solo un medio de prueba dentro de un proceso judicial, sino que es un instrumento para comprender la existencia de pueblos con culturas diferentes, los cambios culturales a su interior y su relación con las distintas instituciones del Estado mexicano.

- Importante para lograr el entendimiento entre lógicas jurídicas, sociales y culturales distintas.

Y se requiere para:

- Garantizar el acceso a la justicia del estado...

+ ... se tomarán en cuenta sus usos y costumbres...

- ...que tengan conocimiento de su lengua y cultura...

- Cuando se trate de personas integrantes de pueblos o comunidades indígenas, el intérprete, además de tener conocimiento de su lengua, deberá conocer sus usos y costumbres.

- Tratándose de personas pertenecientes a los pueblos o comunidades indígenas, tanto el defensor como el intérprete correspondiente deberán tener pleno conocimiento de su lengua y cultura.

\section{La participación política en Oxchuc}

\section{El contexto étnico cultural y sociopolitico}

Araceli Burguete (2016) atribuye el origen del conflicto en Oxchuc, Chiapas, al control político que descansa en estructuras caciquiles de poder y dominación, ya que quienes lo disputan son las familias que se han repartido el poder en los últimos 20 años en el municipio tseltal.

Un rasgo de la estructura de poder y de dominación en Oxchuc es su conformación caciquil de estas familias; de rasgos de impunidad; de usar los recursos públicos y sus redes de poder institucional y con los medios de comunicación, para sostener el poder en las manos de los miembros de la familia. 
En los últimos quince años estas dos familias han tenido el poder municipal en sus manos. Con excepción de Cecilia López Sánchez, que no formaba parte de esos grupos familiares de poder; aunque después, en el contexto local, hizo alianza con la familia Sántiz Gómez, sumándose a la confrontación entre los dos grupos.

El clan al que pertenece la ex presidenta municipal María Gloria Sánchez ha buscado mantener su control a punto de asesinatos ejemplares, hostigamientos en las comunidades y ataques armados en la cabecera municipal que ha dejado alrededor de 20 desaparecidos, por lo menos 3 asesinados y una cantidad importante de heridos. Los asesinatos selectivos han estado dirigidos al Movimiento con Justicia y Paz para el pueblo de Oxchuc, desde donde se han presentado amparos promovidos para rechazar la presencia de partidos políticos en el municipio, así como un amparo contra la ejecución en su territorio de la Ley de Seguridad Interior (Burguete, 2016).

A este análisis se agrega que ese fuerte cacicazgo y férreo control partidista han sido parte de la forma de gobernar del PRI en Oxchuc, al igual que en otros municipios de población mayoritariamente indígena como Chamula, Cancuc, Larráinzar, Tenejapa, y Chenalhó.

Otra característica común a estos poblados es que prácticamente las tierras de todos ellos están integradas en un solo núcleo agrario, a diferencia de municipios como Ocosingo, Altamirano o Venustiano Carranza, con población mayoritariamente indígena, pero en cuya demarcación municipal hay más de un núcleo agrario.

Para poder apreciar las fuentes del conflicto actual hay que tener presentes varios esfuerzos políticos anteriores que combatieron el control priista al nivel municipal. En 1988 se cimbró a la clase política a nivel nacional con el Frente Democrático Nacional (FDN). Sin embargo, la "primavera democrática" encabezada o aglutinada en dicho frente no alcanzó a llegar al sur ni al sureste del país, manteniéndose Chiapas como el gran reservorio de votos plurinominales del PRI, con los municipios indígenas como ejemplo de esto.

Llegando al año 1994, el levantamiento Zapatista trastocó el control político total de Chiapas para el PRI. Lo que derivó inmediatamente en el reemplazo del gobierno que hasta 1994 tenía las siglas de ese partido, por candidatos ex priistas arropados en los colores azul, amarillo, naranja y hace cincos años en la última elección para la gubernatura de verde, con el Partido Verde de México.

Con estos momentos de parteaguas, las bases tradicionales priistas se dislocaron provocando un efecto de desequilibrio en las dinámicas de sucesión del poder 
a nivel municipal y comunitario que había existido por lo menos los últimos 70 años. Esto, aunado al hartazgo en los pobladores por los métodos de control y la profundización de las políticas gubernamentales de (des)re-regulación (Cruz 2013) que detonó la pobreza, dio lugar a los resultados que ahora se pueden observar y que tienen que ver con una mayor exigibilidad de los derechos humanos, y sobre todo civiles y políticos, desde los indígenas, sus organizaciones, comunidades y pueblos.

En el municipio Oxchuc la lucha por el control político en los últimos veinte años involucra diferentes actores, un grupo significativo es el de profesionistas indígenas, quienes dejaron el pueblo durante un buen tiempo y regresan para buscar un espacio de poder.

La interacción de todas las agrupaciones que buscan ese poder ha generado conflictos que implican agresiones hacia quien presida el ayuntamiento; quema de su vivienda; destrucción del edificio de la presidencia municipal y de vehículo; violencia en la celebración de los plebiscitos, ocurriendo a veces la muerte de participantes; exclusión radical de sus opositores en los espacios del ayuntamiento; tomar al presupuesto municipal como un botín; polarización de la sociedad Oxchuquera en uno u otro bando; faccionalismo al seno de las comunidades a las que se les exigen lealtades políticas para aplicar políticas sociales clientelares; imposición de agentes y comités municipales en las comunidades, afines al presidente municipal en turno y creciente intervención de los partidos políticos que han contribuido a profundizar el cuadro de conflictos (Jiménez y Ocampo, 2019: 57).

Oxchuc es ejemplo de los intentos del priismo por no perder el poder al ser cuestionado por la movilización que propició el FDN en 1988 y el EZLN en 1994. De esta manera, los desequilibrios que ahora se ven y sus secuelas se gestaron en ese periodo, dando como resultado un trastocamiento en las dinámicas internas/comunitarias de sucesión en el poder:

El conflicto que ahora se presenta está relacionado con la pérdida de los equilibrios de poder que anteriormente se lograba al integrar el ayuntamiento municipal de una manera plural, incorporando la representación de los barrios, las regiones y los linajes.

Esos equilibrios se lograban en los ejercicios de acuerdos previos entre los grupos, mediados por los principales; incorporando la alternancia de la autoridad entre los 
barrios, y a través de las asambleas, que era el lugar en donde se dirimían las jerarquías de los espacios de poder. En esta lógica, idealmente todos ganaban.

El que tenía mayor votación ocupaba el cargo de presidente municipal; el que le seguía en votos, el cargo de síndico; luego el siguiente el cargo de tesorero; luego juez; primer regidor y así sucesivamente.

Pero esta forma de organización de la distribución del poder se perdió. En los últimos quince años comienza una lucha de poder entre dos grupos familiares que han secuestrado el ayuntamiento municipal, imponiendo sus intereses particulares (Burguete, 2016).

Finalmente tal desequilibrio se enrarece porque, al igual que los indígenas y sus pueblos, han aprovechado un uso contestatario del derecho positivo. La clase política gobernante ha aprendido a utilizar e invocar en su beneficio acuerdos, cláusulas políticas y acciones afirmativas relacionadas con los derechos humanos (por ejemplo, María Gloria Sánchez que, dada su condición de género, se autopronuncia víctima de discriminacion, mientras ignora las violaciones a los derechos de otros y otras indígenas en el contexto histórico, político y étnico cultural).

\section{Resolución del Tribunal Electoral del Estado de Chiapas: una cronología}

Hechos jurídicos previos a la sentencia del Tribunal Electoral del Estado de Chiapas y que consisten en la solicitud al Instituto de Elecciones y Participación Ciudadana, para la elección de autoridades municipales, por el sistema normativo de usos y costumbres en Oxchuc, Chiapas

El II de noviembre de 20I6, la Comisión Permanente por la Paz y Justicia de Oxchuc, y Tres Nudos, Asociación Civil (A.C.) - sector organizado de ciudadanos indígenas de Oxchuc-, solicitaron por separado al Instituto de Elecciones y Participación Ciudadana (IEPC) que en el periodo 2019-202I se llevara a cabo la elección del $\mathrm{H}$. Ayuntamiento de su municipio a través del sistema normativo de usos y costumbres.

El IEPC respondió a esa solicitud en sentido negativo el io de febrero de 2017 , argumentando su improcedencia, toda vez que no existe regulación en la legislación estatal sobre elección de autoridades por usos y costumbres, por lo que en estricto derecho no existen autoridades competentes para iniciar el proceso de consulta 
que conlleve al cambio del sistema de partidos al sistema indígena. Por lo tanto, el IEPC sostuvo que no es la autoridad facultada para iniciar un proceso o celebrar alguna asamblea en Oxchuc para ese propósito, y agregó que no hay condiciones sociales necesarias para realizar una consulta. El IEPC señaló que las condiciones sociales son de tensión, derivadas de la disputa que existe para la integración de la autoridad municipal.

En esa respuesta el IEPC no solo ignoró los derechos indígenas, sino que pasó por alto el principio pro persona reconocido desde 20II, en el bloque de constitucionalidad de derechos humanos de la CPEUM.

También, para las fechas en que emite su resolución, la presidencia de la SCJN (2014) había publicado el Protocolo de actuación para quienes imparten justicia en casos que involucren derechos de personas, comunidades y pueblos indígenas, donde se señala que dicho protocolo:

[...] tiene como única finalidad servir como herramienta orientadora al impartidor de justicia para que, en uso de sus facultades constitucionales y en estricto ejercicio de su independencia y autonomía, encuentre más elementos para lograr una justicia más accesible y un conocimiento de los asuntos que se desarrollan en un contexto de pluralidad cultural para emitir resoluciones que salvaguarden de la mejor manera posible derechos reconocidos.

Es decir, la autoridad no puede invocar ignorancia de la ley para justificar su incumplimiento, más si existían guías emitidas para incorporar a las actuaciones de las autoridades jurisdiccionales y administrativas no solo el discurso de derechos humanos, sino los mecanismos para su cumplimiento.

Hechos jurídicos dentro del Juicio para la Protección de los Derechos Político-Electorales del Ciudadano y que da lugar a la sentencia del Tribunal Electoral del Estado de Chiapas

Ante la respuesta del Iepc, el 8 de marzo de 2017 la Comisión Permanente por la Paz y Justicia de Oxchuc y Tres Nudos, A.C., promovieron por separado juicios para la protección de los derechos político-electorales del ciudadano, ante la Sala Superior del Tribunal Electoral del Poder Judicial de la Federación, vía per saltum (saltando la instancia del Tribunal Electoral del Estado de Chiapas). Por ello, el 4 de abril de 2017 dicha sala los declaró improcedentes y determinó reencauzarlos a efecto de que el Teech conociera de las demandas. De esta manera, el i6 de abril de 2017, el TeEch fue notificado. 
El I7 de abril de 2017 el tribunal tuvo por recibidos los juicios de derechos ciudadanos y los remitió al magistrado en turno, instructor Guillermo Asseburg Archila, para que le diera trámite legal, por lo que el ig de abril de 20I7, este requirió a los actores para que señalaran domicilio donde serían notificados, apercibiéndolos que, de no hacerlo, en lo subsecuente serían notificados en los estrados del tribunal.

Dado que la Comisión Permanente por la Paz y Justicia de Oxchuc y Tres Nudos, A.C. no respondieron al apercibimiento, el magistrado instructor hizo efectivo el apercibimiento a los actores notificándolos en los estrados del TEEch, sentencia de fecha 2 de mayo de 20I7, ratificando la improcedencia de su demanda de protección de derechos previsto en el artículo 404 del Código de Elecciones y Participación Ciudadana y ordenó se elaborara el acuerdo colegiado para la denegación de admisión de los juicios de protección de derechos ciudadanos.

La postura del magistrado para una autoridad no es dable como justificación, puesto que no consideró el principio de suplencia de la queja (según los artículos 79 al 85 de la Ley General del Sistema de Medios de Impugnación en Materia Electoral) y mucho menos el principio pro persona, y en un intento por remediar la postura del I2 de mayo de 20I7, en sesión pública el Pleno del Teech por unanimidad acordó retirar el proyecto presentado por el magistrado instructor, $y$ dar entrada a los juicios ciudadanos, analizarlos a fondo, y en consecuencia se revocó el acuerdo del 2 de mayo de 2017. Por ello, el I8 de mayo de 2017 el magistrado instructor determinó dar por recibidos los expedientes y dar trámite a los medios de impugnación presentados.

A partir del I5 de junio de 2017 se procedió al desahogo y la admisión de pruebas ofrecidas, $y$ las autoridades judiciales expusieron en su plenitud el principio pro persona y de suplencia de la queja, así como los derechos de los pueblos indígenas a la libre determinación y al derecho a la consulta. Todo esto se encuentra fundado en el andamiaje jurídico nacional encabezado por la CPEUM (artículos $\mathrm{I}^{\circ}, 2^{\circ}, 133$ ), en jurisprudencias de la Sala Superior del Tribunal Electoral del Poder Judicial de la Federación, y en el artículo $7^{\circ}$ de la cPEchis. De igual forma, en el andamiaje internacional empezando con el Ci69, la Declaración, el Pacto Internacional de Derechos Civiles y Políticos y el Pacto Internacional de Derechos Económicos, Sociales y Culturales.

Con fecha 28 de junio de 2017 el Pleno del TeEch dictó la sentencia: proteger los derechos de la Comisión Permanente por la Paz y Justicia de Oxchuc, así como de Tres Nudos, A.C., y revocar el acuerdo del IEPC/CG-A/005/20I7 de fecha Io de febrero de 2017. En esta sentencia se señaló que la autoridad responsable de ejecutarla es el IEPC, con actividades concretas: 
i. Determinar la viabilidad de la implementación del sistema de usos y costumbres de dicha comunidad para la elección de sus autoridades. Verificar por todos los medios atinentes información objetiva, que demuestre la existencia histórica de un sistema interno acorde al marco constitucional de los derechos humanos, para lo cual podrá solicitar la realización de dictámenes, informes de autoridades, federales, estatales y municipales legales y tradicionales, así como estudios antropológicos;

ii. Deberá allegarse de información, a través de los procedimientos idóneos, sobre las condiciones sociales, políticas, económicas, de seguridad y demás como pudiera ser cualquier situación que prevalezca en esa comunidad entorno a su estabilidad social; $y$

iii. Una vez realizadas las acciones señaladas el IEPC deberá dar respuesta de manera fundada y motivada, a la petición de la Comisión Permanente por la Paz y Justicia de Oxchuc, planteada en el escrito de 2 de septiembre de 2016 y que inexcusablemente deberá considerar, los principios y requisitos establecidos en el Ci69, conforme a los cuales las consultas a los pueblos indígenas deberán hacerse en las cuestiones que les afectan, tales principios de la consulta son* I. Endógeno; 2. Libre; 3. Pacifico; 4. Informado; 5. Democrático; 6. Equitativo. 7. Socialmente Responsable y 8. Autogestionado.

Hechos jurídicos posteriores a la sentencia que resultó del Juicio para la Protección de los Derechos Politicos Electorales del Ciudadano

Sin embargo transcurridos cinco meses sin luces de la ejecución de tal sentencia, el I7 de noviembre de 2017, Juan Encino Gómez y Juan Gabriel Méndez López presentaron ante el TEEch un Incidente de Ejecución de Sentencia derivado del expediente $\mathrm{TEECH} / \mathrm{JDC} / \mathrm{I} / 20 \mathrm{O} 7$, en el que manifestaron que el IEPC no estaba cumpliendo en tiempo y forma la dicha sentencia, argumentando que a casi cinco meses no se había hecho el peritaje/dictamen antropológico y menos se había realizado la consulta.

Ante eso, con fecha 22 de noviembre de 2017 el TEech admitió a trámite el Incidente requiriendo al IEPC, como autoridad responsable, manifestara lo que a su interés conviniera en relación a las prestaciones reclamadas, contando con cinco días a partir de la notificación para presentar su respuesta.

El 4 de diciembre de 20I7, la autoridad responsable hizo entrega del Informe requerido por el TEECh, con lo que el 29 de diciembre de 2017 se emitió sentencia del Incidente de Incumplimiento de Sentencia derivado de los expedientes TEECH/ JDC/OI9/20I7 y acumulados por el TEEch, en donde el juzgador se dio por satisfecho 
con el informe justificado del IEPC, y este justificó el retraso en el incumplimiento de la sentencia, la falta de presupuesto ya que la Secretaria de Hacienda de Chiapas no había entregado los recursos solicitados y por lo que manifestó en su informe que se encontraba en vías de cumplimiento.

El lunes ig de febrero de 2018 se liberó una orden de aprehensión en contra de María Gloria Sánchez y su cabildo (Henriquez, 2019).

\section{El dictamen antropológico y la consulta ciudadana, un recuento}

El dictamen antropológico consistió en una investigación in situ en la cabecera y las comunidades del municipio de Oxchuc para determinar si efectivamente el pueblo tseltal elije o elegía por usos y costumbres a sus autoridades, cómo es este mecanismo y en qué puntos existe intersección con el sistema estatal de partidos políticos.

De acuerdo con Jiménez y Ocampo (2019) las particularidades del sistema de elección de autoridades por usos y costumbres en la actualidad en Oxchuc son:

Las asambleas actualmente se realizan para abordar asuntos relevantes y se deben convocar con al menos quince días de anticipación; todas las autoridades municipales que concluyen el cargo en 2018 se eligieron mediante asamblea.

Por su parte en las comunidades y parajes de Oxchuc existe un sistema de cargos, que es el mecanismo mediante el cual se accede a puestos de autoridad, que forma parte de lo que localmente se denomina "el costumbre".

Dicho sistema es una estructura escalafonaria para el cumplimiento de encomiendas y supone una serie de requisitos para el acceso y para el ascenso en ella. La estructura de autoridad comunitaria se basa en tres figuras relevantes: los principales, el agente auxiliar y el comité de educación.

El grupo de los principales está formado por las autoridades anteriores que son los miembros de la comunidad que han cumplido ya con todos los cargos de servicio. En la medida en que han obtenido el reconocimiento y respeto de la comunidad, son autoridades morales y políticas. Tradicionalmente son quienes proponen a las personas que habrán de ocupar cargos comunitarios y los presentan ante la asamblea, de igual forma se encargan de visitarlos y pedirles que acepten. 
Se considera que los principales por su experiencia pueden escoger a la gente idónea para los cargos. Los principales fungen como el aval moral de quienes son propuestos para los cargos, pero no son ellos mismos parte del sistema de cargos sino quienes lo han terminado exitosamente. El número de principales varía en cada comunidad.

La autoridad mayor a nivel comunidad es el agente auxiliar o agente municipal, máximo cargo que se puede tener dentro de una comunidad del municipio de Oxchuc; éste se encarga de resolver conflictos dentro de la comunidad y realizar gestiones ante el municipio; no cuenta con autonomía en la toma de decisiones porque realiza actividades que le son asignadas por la asamblea comunitaria, ante la cual, a su vez, deberá rendir cuentas. A ello se suma la existencia de reglamentos internos, muchas veces escritos, que delimitan las acciones del conjunto de autoridades comunitarias o municipales (Jiménez y Ocampo, 2019: 55-56).

Es relevante del dictamen de los expertos del INAH, la parte de sus conclusiones:

De acuerdo con el objetivo del presente dictamen, el sistema normativo interno que regula las formas de gobierno indígena en el municipio de Oxchuc, mantiene su vigencia y particularidades en la cabecera municipal y en las comunidades, no obstante haber experimentado cambios en las últimas décadas.

Los cambios experimentados en este sistema de cargos no son prueba de su debilitamiento, sino más bien de su capacidad de adaptación a las nuevas condiciones y circunstancias políticas, características que lo hacen dinámico y permiten su pervivencia, como otros sistemas políticos entre ellos nacional (sic) (Magchun et al., 2018:34).

Sobre la consulta ciudadana y de acuerdo con la información publicitada por el propio Instituto Estatal Electoral, a través de la expedición del acuerdo IEPC/ CG-A/or6/2019 y con notas periodística del Instituto Nacional de Pueblos Indígenas (INPI), el proceso de consulta fue el siguiente: 


\section{Consultas informativas}

Se efectuaron asambleas comunitarias del 5 al 20 de noviembre de 2018 que consistieron en informar en cada localidad sobre las etapas, el desarrollo y las fechas que comprende el proceso de consulta, así como los requisitos para participar en ellas (López, 2018). En esas asambleas informativas además se eligieron dos representantes propietarios y dos suplentes, en ambos casos uno por género, y se señalaron las fechas para la celebración de las asambleas comunitarias de consulta. También se acordó en esas asambleas informativas la forma en que se tomaría el consenso sobre el sistema de elección de autoridades municipales (acordándose que puede ser a mano alzada, por pizarrón y urna).

\section{Consultas para decidir cambio de sistema}

Para el 27 de septiembre se efectuó asamblea de consulta en cinco comunidades, el 28 en otras cinco, el 29 en cuatro y el 30 de ese mes se atendieron cuatro más; y en octubre, los días 2 y 3 en seis cada día, el 4 en cinco y el día 5 se cubrió una sola localidad. En diciembre las consultas para decidir cambio de sistema se realizaron de la siguiente manera: el 6 de diciembre en seis; el 7 en seis; el 8 en cinco; el 9 en cuatro; el Io en seis; el ir en una; el I2 en cuatro; el iz en cuatro; el i4 en dos; el I5 en tres; el I6 en cinco; el I7 en seis; el I8 en cinco; el 20 en cinco; el $2 \mathrm{I}$ en cinco; el 22 en cuatro; el 26 en dos; el 27 en cuatro; el 28 en tres; el 29 en una, y el 30 en una.

$\mathrm{El} 5$ de enero de 2019 se celebró en el Auditorio Municipal de Oxchuc, Chiapas, la Asamblea Plenaria de Resultados del Proceso de Consulta por el que la ciudadanía de dicho municipio determinó el sistema mediante el cual elegirán a sus autoridades municipales, arrojando como resultado 59.17831190609 por ciento ([sic] punto I de Antecedentes del Acuerdo IEPC/CG-A/or6/2019) a favor del sistema normativo interno (usos y costumbres), lo que corresponde a 69 localidades, por encima del sistema de partidos políticos (con un 38.39575181666 por ciento), que representa 47 localidades; en tanto que, se registró un 2.45593627725 por ciento de Asambleas de Consulta no celebradas correspondiendo a cuatro localidades.

Con base en los acuerdos expedidos por el IEPC podemos ilustrar la línea de tiempo del proceso de elección de autoridades posterior a las consultas de esta manera: 


\section{ILUSTRACIÓN 9.}

Linea de tiempo, entrega de resultados de consulta e inicio del proceso para la elección por usos y costumbres.

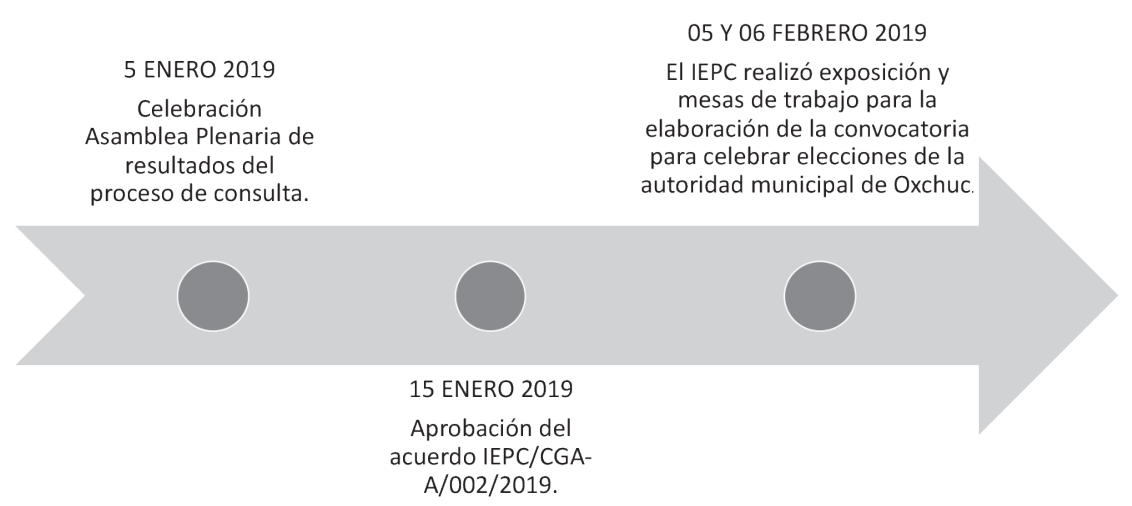

Elaboración propia.

\section{ILUSTRACIÓN IO.}

Linea de tiempo para inicio del proceso de elección de autoridades.

11 FEBRERO 2019

IEPC aprueba la

convocatoria a la ciudadanía para elegir a sus autoridades municipales.
28 FEBRERO 2019

Mediante oficio IEPC SE. DEPC012.2019 se realizan manifestaciones respecto al proceso de elección de autoridades municipales.

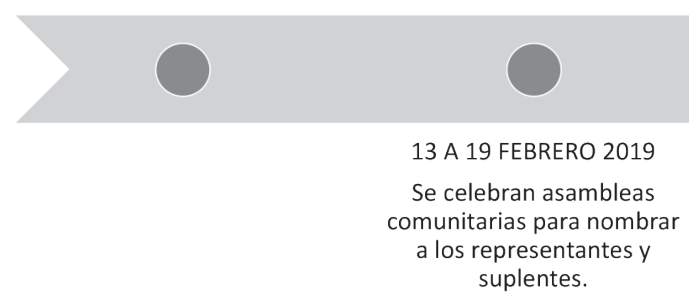




\section{ILUSTRACIÓN II.}

Formulación de recomendaciones y normas para la elección.

01 MARZO 2019

En el DIF, se presentan

recomendaciones para $\mathrm{e}$

\section{MARZO 2019}

La Asamblea General reanuda sesión sobre los puntos con

respecto a la temporalidad del

cargo, postulación de

candidatos y candidatas.

\section{Elección}

Según la nota que difunde el INPI, alrededor de I2 000 representantes participaron en el histórico proceso de elecciones realizadas en el municipio tseltal de Oxchuc, Chiapas. Señalando que a esa Asamblea Plenaria concurrieron II 92I ciudadanos, ciudadanas y representantes, de II5 comunidades y 14 barrios para elegir a las y los integrantes del ayuntamiento.

\section{Elección de autoridades por usos y costumbres}

\section{De acuerdo con nota periodística de Elio Henríquez (2019):}

Desde las 8 horas comenzaron a llegar los habitantes para registrarse con la credencial de elector y participar en las elecciones que mediante la asamblea se realizaron a partir de las i3 horas en la plaza central de Oxchuc.

Poco después del mediodía, los integrantes de la mesa de debates de la asamblea dieron a conocer que se habían registrado II mil 92I ciudadanos, de un padrón de 35 mil 843 electores, de las i2o localidades del municipio, ubicado en los Altos de Chiapas. 
A las iz horas, el presidente de la mesa de debates, Francisco Sántiz Gómez leyó uno por uno durante tres veces los nombres de las cinco mujeres y cuatro varones para que los pobladores asistentes levantaran la mano por su candidato preferido.

Alfredo Sántiz Gómez, de 42 años de edad, fue el que tuvo una mayoría visible, por lo que fue declarado ganador de las elecciones, y en seguida se realizó el mismo procedimiento para elegir a la síndica y a las y los regidores que conformarán el cabildo que tomará posesión del 23 de este mes, para concluir el trienio que empezó el i de octubre pasado. Esta es la primera vez que las autoridades de algún municipio de Chiapas son elegidas mediante el sistema de usos y costumbres.

\section{ILUSTRACIÓN I2.}

Elección de autoridades por usos y costumbres (13 de abril de 2019).

13 ABRIL 2019

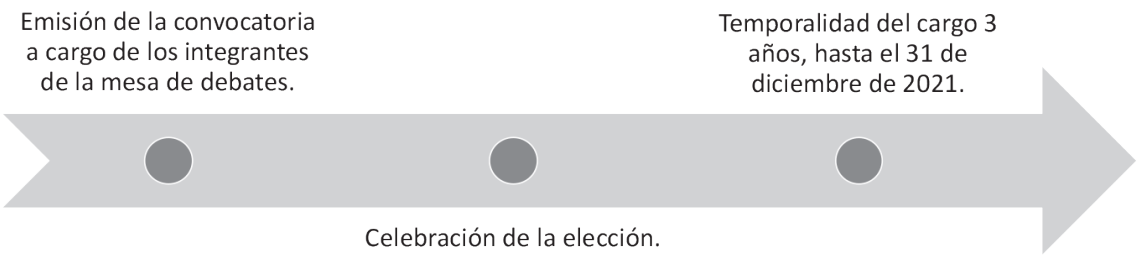

Elaboración propia.

De igual forma se señala que para el cargo de presidente concejal municipal participaron Io candidatos: cinco mujeres y cinco hombres, cumpliendo la paridad en la postulación de candidatos. Con votación a mano alzada eligieron al profesor Alfredo Sántiz Gómez como su presidente municipal e integraron el ayuntamiento en forma paritaria, horizontal y vertical.

La autoridad electa quedó integrada por ocho mujeres y siete hombres de diversas comunidades del municipio, tomaron posesión de sus cargos el 23 de abril y culminarán en diciembre del año 2021.

\section{Reflexiones finales}

Coincidimos en parte con lo que Jiménez y Ocampo (2019) señalan como puntos de interlegalidad y coexistencia entre el sistema de elección interno de Oxchuc y el sistema electoral estatal. 
La disputa del gobierno municipal en Oxchuc es una de las expresiones de un tema profundo que es la gobernanza pues ésta resultó seriamente afectada desde la llegada de los partidos políticos y la desaparición del mecanismo de elección en asamblea, sin embargo, en el actual contexto político de Oxchuc coexisten el derecho electoral indígena integrado por normas, principios y procedimientos originarios y las reglas del sistema electoral mexicano, esto gracias a la intervención del TEPJF.

Las ciudadanas y los ciudadanos de Oxchuc se encuentran sometidos a un sistema interno para la elección de autoridades que quizá no coincide con los principios que sustentan los derechos políticos que protege y garantiza el sistema electoral mexicano, pero en la práctica las decisiones de la asamblea general comunitaria, por ejemplo, han sido más efectivas y plurales que las tomadas por la autoridad electoral hegemónica.

Sin embargo, al terminar de redactar este trabajo (noviembre de 2019) el escenario en el que se desarrolla el nuevo gobierno municipal electo por el sistema de usos y costumbres parece reeditar los conflictos políticos de antaño entre facciones y grupos. El análisis de este ejercicio de gobierno como expresión de la autonomía dará lugar a muchos más análisis, por lo que solo adelantamos que tal cual sucedió con el sistema de elección por usos y costumbres en Oaxaca, el gatopardismo entró en acción: cambiar todo para que quede igual.

Partidos de oposición, organizaciones indígenas y autoridades municipales se movilizan buscando cada uno orientar en su provecho el cambio político. La aplicación de la nueva legislación conlleva efectos tan contradictorios como las razones que motivaron su creación. Lejos de garantizar un status quo político, la oficialización de las costumbres implica nuevos conflictos y acentúa la descomposición del modo de dominación instalado después de la Revolución, en los años treinta. Parece surgir a nivel local un nuevo orden político, incierto, ambivalente, un orden que pasa principalmente por la recomposición interna de las comunidades y la producción negociada de una nueva costumbre (Recondo, 2007:29).

Y esto se observa en los modos de hacer política al interior de Oxchuc, excluyendo a los opositores y manteniendo el monopolio en las decisiones que afectan o atañen a las comunidades que integran el municipio.

Y a pesar de que para unos el trabajo de Recondo (2007) en su época solo aplicaba para el caso de Oaxaca, porque el reclamo de cambio de sistema de partido era exclusivo de la realidad oaxaqueña, hoy por hoy se ve más actualizado que nunca: 
Afortunadamente la importancia del libro de David Recondo, La politica del gatopardo/Multiculturalismo y democracia en Oaxaca, no radica en su contribución al debate sobre la conveniencia de implantar elecciones mediante usos y costumbres en las regiones indígenas del país; de lo contrario sólo cabría lamentar su tardía aparición. En efecto, dicho debate parece haber perdido toda vigencia. No parece que ningún estado de la república tenga la intención de seguir el camino - o más bien el callejón sin salida- en que se adentró Oaxaca en 1995 (Viqueira, 2008).

Es decir, tal vez cambiaron las normas estatales para incorporar las exigencias indígenas de este municipio, pero faltará mucho más tiempo para cambiar las dinámicas y los modos en que los pobladores indígenas han aprendido desde hace más de 90 años, tomando lo peor o lo mejor del sistema político mexicano.

\section{Referencias bibliográficas}

\section{Aristegui Noticias}

2018 Cabildo de Oxchuc interpone amparo en contra de la Ley de Seguridad Interior. Recuperado de: <https://aristeguinoticias.com/220I/mexico/ cabildo-de-oxchuc-chiapas-presenta-amparo-contra-ley-de-seguridad-interior-video/> [consulta: 02/o6/2018].

Burguete Cal y Mayor, Araceli

2011 "Municipalización del gobierno indígena e indianización del gobierno municipal en América Latina", Revista Pueblos y fronteras digital 6 (II). Disponible en: <http://www.redalyc.org/articulo.oa?id=90618647003> [consulta: 16/o6/2016].

2016 “Por qué es conveniente una elección de "usos y costumbres” en Oxchuc?", Chiapas Paralelo, 22 de febrero <https: //www.chiapasparalelo.com/opinion/2016/o2/por-que-es-conveniente-una-eleccion-deusos-y-costumbres-en-oxchuc/> [consulta: I3/II/20I9].

2017 "Gana Oxchuc en el Tribunal Electoral. Va por elecciones de Usos y Costumbres", Chiapas Paralelo, 3 de julio. Recuperado de: <https:// www.chiapasparalelo.com/opinion/2017/07/gana-oxchuc-en-el-tribunal-electoral-va-por-elecciones-de-usos-y-costumbres $/>$ [consulta: 10/05/2018].

Cámara de Diputados del H. Congreso de la Unión 
2017 Ley General de Instituciones y Procedimientos Electorales. Recuperado de: <www.iepc-chiapas.org.mx/archivos/legislacion/NORMATIVIDAD_ VIGENTE/OI_NORMATIVIDAD_FEDERAL/O2_LEY_GENERAL_DE_INSTITUCIONES_Y_PROCEDIMIENTOS_ELECTORALES.pdf $>$ [consulta: I4/05/2018].

Comisión Nacional de Derechos Humanos

2016 Recomendación General núm. 27/2016 sobre el derecho a la consulta previa de los pueblos y comunidades indígenas de la República mexicana, Diario Oficial de la Federación. Recuperado de: <http://www. cndh.org.mx/sites/all/doc/Recomendaciones/generales/RecGral_027. pdf> [consulta: 06/05/2018].

Cruz Rueda Elisa y Long Natalie

(en prensa) "El derecho de los pueblos indígenas a ser consultados: El caso de Oxchuc, Chiapas", en Juan Jorge Faundes y Silvina Ramírez (eds.), Derecho fundamental a la identidad cultural, abordajes plurales desde América Latina, Santiago, Universidad Autónoma de Chile.

Cruz Rueda, Elisa

2013 "Derecho a la tierra y el territorio: demandas indígenas, Estado y capital en el Istmo de Tehuantepec", en María Teresa Sierra Camacho, Rosalva Aída Hernández y Rachel Sieder (eds.), Justicia indígena y estado. Violencias contemporáneas, México, Flacso-México/ciesas, pp. 34I-382.

Cruz Rueda, Elisa y Ma. Eugenia Santana

2008 "Mecanismos de consulta a los pueblos indígenas en el marco del convenio I69 de la oit: el caso mexicano", Revista Pueblos y fronteras digital, 5, pp. I-38. Recuperado de: <http://www.pueblosyfronteras. unam.mx/index.php/index.php/pyf/article/view/208/208> [consulta: 02/06/2018].

2009 "Mecanismos de consulta a los pueblos indígenas en el marco del Convenio 169 de la ort", en E. Sánchez Botero (ed.), Consulta previa. Experiencias de aprendizaje, Bogotá, Instituto Colombiano de Antropología e Historia / Agencia Nacional de Hidrocarburos, pp. I4I-I62.

2013 "Reconocimiento jurídico de la diversidad cultural sin ejercicio de derechos?", Revista Pueblos y fronteras digital, 8(16), pp. 218-255. <https:// doi.org/10.2220I/cimsur.18704115e.2013.16.78>.

Figueroa Gutarra, Edwin

2009 “Principios de interpretación constitucional”, Jurídica, 248, El Peruano, 28 de abril. Recuperado de <https://edwinfigueroag.wordpress. 
com/2010/09/04/principios-de-interpretacion-constitucional/> [consulta: 02/06/2018].

Henríquez, Elio

2019 "Chiapas: Eligen alcalde de Oxchuc por medio de usos y costumbres", La Jornada. Estados, i3 de abril. Recuperado de: < https://www.jornada. com.mx/ultimas/estados/2019/04/13/chiapas-eligen-autoridad-municipal-por-medio-de-usos-y-costumbres-8366.html> [consulta: 31/08/2019].

H. Congreso de la Unión y Cámara de Diputados

20I8a Constitución Política de los Estados Unidos Mexicanos. Recuperado de: <www.diputados.gob.mx/LeyesBiblio/pdf/I_I50917.pdf> [consulta: 18/05/2018].

2018b Ley general del sistema de medios de impugnación en materia electoral. Recuperado de: <http://www.diputados.gob.mx/LeyesBiblio/ref/ lgsmime.htm $>$ [consulta: 06/06/2018].

H. Sexagésima Legislatura del Estado de Chiapas

2014 Ley de Derechos y Cultura Indígenas del Estado de Chiapas CNDH. Fecha de publicación: 29 de julio de 1999. Última reforma integrada: 27 de noviembre de 2014. Recuperado de: <http://cndh.org.mx/sites/all/ doc/Programas/Indigenas/OtrasNormas/Estatal/Chiapas/Ley_DCIchis.pdf> [consulta: 05/05/2018].

H. Sexagésima Sexta Legislatura del Estado de Chiapas

2017a Código de Elecciones y Participación Ciudadana del Estado de Chiapas. Recuperado de: <http://www.iepc-chiapas,org.mx/archivos/ legislacion/NORMATIVIDAD_VIGENTE/O2_NORMATIVIDAD_ESTATAL/ CODIGO_DE_ELECCIONES_Y_PARTICIPACION_CIUDADANA_FE_DE_ ERRATAS_27102017.pdf > [consulta: 10/05/2018].

20I7b Constitución Política del Estado Libre y Soberano de Chiapas. Recuperado de: <http://www.iepc-chiapas.org.mx/archivos/legislacion/ NORMATIVIDAD_VIGENTE/O2_NORMATIVIDAD_ESTATAL/CONSTITUCION_POLITICA_DEL_ESTADO_DE_CHIAPAS_060920I7.pdf $>$ [consulta: 10/05/2018].

Instituto Nacional de Pueblos Indígenas

2019 "Oxchuc, primer municipio de Chiapas que elige a sus autoridades a través del régimen de Sistemas Normativos Indígenas". Recuperado de: <https://www.gob.mx/inpi/articulos/oxchuc-primer-municipio-de-chiapas-que-elige-a-sus-autoridades-a-traves-del-regi- 
men-de-sistemas-normativos-indigenas-197217?idiom=es $>$ [consulta: 31/08/2019].

Instituto Estatal Electoral

2019 Acuerdo IEPC/CG-A/oi6/2019. Recuperado de: <http://www. iepc-chiapas.org.mx/archivos/sesiones/acuerdos/2019/ACUERDO\%2O IEPC.CG-A.0I6.2019.pdf> [consulta: 3I/o8/2019].

Instituto Nacional Electoral

2016 Protocolo para la Consulta a Pueblos y Comunidades Indígenas en materia de Distritación Electoral. Recuperado de: <http://portalanterior.ine. $\mathrm{mx} /$ archivos3/portal/historico/recursos/IFE-v2/DS/DS-CG/DS-SesionescG/CG-acuerdos/2016/o2_Febrero/cGor201602-26/cGor20160226_ap_I4_aI.pdf> [consulta: 18/05/2018].

Jiménez Ojeda, Omar David y Manuel Gustavo Ocampo Muñoa

2019 "El derecho a la libre determinación en materia política y su judicialización. La interlegalidad electoral reconocida en Oxchuc, Chiapas”, en Rodríguez Ortiz y Ortelli, Experiencias contemporáneas de participación politica y ciudadana en México y Colombia, San Cristóbal de las Casas, Chiapas, Universidad Autónoma de Chiapas/Editorial Fray Bartolomé de las Casas.

López, Isai

2018 "En marcha consulta ciudadana en Oxchuc. Determinarán método de elección de autoridades municipales", El Heraldo de Chiapas, sección Local, 28 de noviembre. Recuperado de: <https://www.elheraldodechiapas.com. mx/local/en-marcha-consulta-ciudadana-en-oxchuc-2730567.html> [consulta: 31/08/2019].

Megchun, Rodrigo, Teresa Mora, Héctor Ortiz y Xóchitl Zolueta

2018 Dictamen antropológico. Sistema normativo indígena para la designación de autoridades en el municipio de Santo Tomás Oxchuc, México, Instituto Nacional de Antropología e Historia.

Organización Internacional del Trabajo oIT

1989 Convenio 169 de la Organización Internacional del Trabajo para pueblos indígenas y tribales en países independientes, Ginebra. Recuperado de: $<$ http://www.ilo.org/wcmsp5/groups/public/@ed_norm/@normes/ documents/publication/wcms_ioogro.pdf> [consulta: 18/05/2018].

Presidencia de la República 
2013 "Reforma energética. Toda nuestra energía para mover a México". Recuperado de: <http://presidencia.gob.mx/reformaenergetica/\#!landing > [consulta: 18/05/2018].

Presidencia de la Suprema Corte de Justicia de la Nación scjN

2014 Protocolo de actuación para quienes imparten justicia en casos que involucren derechos de personas, comunidades y pueblos indígenas. Suprema Corte de Justicia de la Nación. México. Recuperado de: <https:// www.sitios.scjn.gob.mx/codhap/sites/default/files/archivos/paginas/ nueva_version_ProtocoloIndigenasDig.pdf> [consulta: 06/05/2018].

Recondo, David

2007 La política del gatopardo. Multiculturalismo y democracia en Oaxaca, México, Centro de Investigaciones y Estudios Superiores en Antropología Social/Centro de Estudio Mexicanos y Centroamericanos.

Rus, Jan

1995 "La comunidad revolucionaria institucional: la subversión del gobierno indígena en los Altos de Chiapas, 1936-1968", en: Juan Pedro Viqueira y Mario Humberto Ruz (eds.), Chiapas. Los rumbos de otra historia, UNAM/CIESAS.

Sieder, Rachel y María Teresa Sierra

2011 "Acceso a la justicia para las mujeres indígenas en América Latina ," CMI working paper, Chr. Michelsen Institute, Bergen. Disponible en: $<$ http://www.rachelsieder.com/wpcontent/uploads/2015/or/Acceso-a-la-justicia-para-las-mujeresindi\%cc\%8Igenas-en-Ame\%cc\%8Irica-Latina.pdf> [consulta: 14/06/2016].

Viqueira, Juan Pedro

2008 "La política del gatopardo / Multiculturalismo y democracia en Oaxaca, de David Recondo", reseña en Letras Libres, 3I de julio, en: < https:// www.letraslibres.com/mexico/libros/la-politica-del-gatopardo-multiculturalismo-y-democracia-en-oaxaca-david-recondo $>$ [consulta: I4/II/2019].

Elisa Cruz Rueda

Abogada y antropóloga. Licenciada en Derecho por la Universidad Nacional Autónoma de México, maestra y doctora en Ciencias Antropológicas por la Universidad Autónoma Metropolitana Unidad Iztapalapa. Profesora e Investigadora de Tiempo Completo en la Licenciatura en Gestión y Autodesarrollo Indígena de la Universidad Autónoma de Chiapas, Campus in San Cristóbal de las Casas Chiapas. Miembro 
del Sistema Nacional de Investigadores del Consejo Nacional de Ciencia y Tecnología, nivel I. Sus líneas de investigación se definen en torno a Derechos Humanos, Pueblos Indígenas, Políticas Públicas en y para la Diversidad. elisacruzrueda@ hotmail.com

Natalie Long

Abogada Litigante de materia ambiental, Springfield, Estado de Illinois, Estados Unidos. Licenciada en Derecho, con Certificado en Derecho Internacional y Comparado, por la Facultad de Derecho de la Universidad de DePaul, Chicago, Estado de Illinois, Estados Unidos. Sus líneas de investigación: Derechos Humanos, Derechos Ambiental, Prácticas Autónomas y Autogestivas. long.natalie@gmail.com

Citar como: Elisa Cruz Rueda y Natalie Long (2020), “Oxchuc, Chiapas: representación política y peritaje antropológico", Iztapalapa. Revista de Ciencias Sociales y Humanidades, núm. 89, año 4I, julio-diciembre de 2020, ISSN: 2007-9176; pp.97-130. Disponible en <http://revistaiztapalapa.izt.uam.mx/ index.php/izt/issue/archive $>$. 